
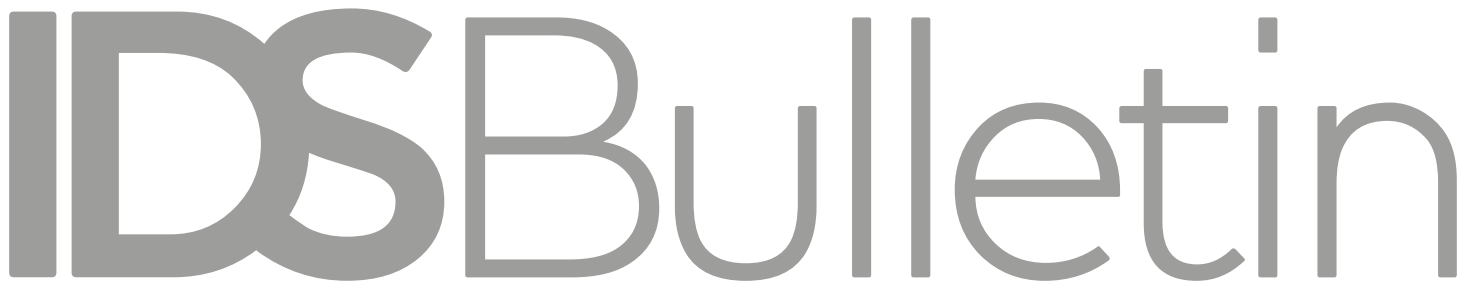

Transforming

Development Knouledge

Volume 49 | Number 3 | July 2018

\title{
EMERGING ECONOMIES AND THE CHANGING DYNAMICS OF DEVELOPMENT COOPERATION
}

Editors Jing Gu and Naohiro Kitano

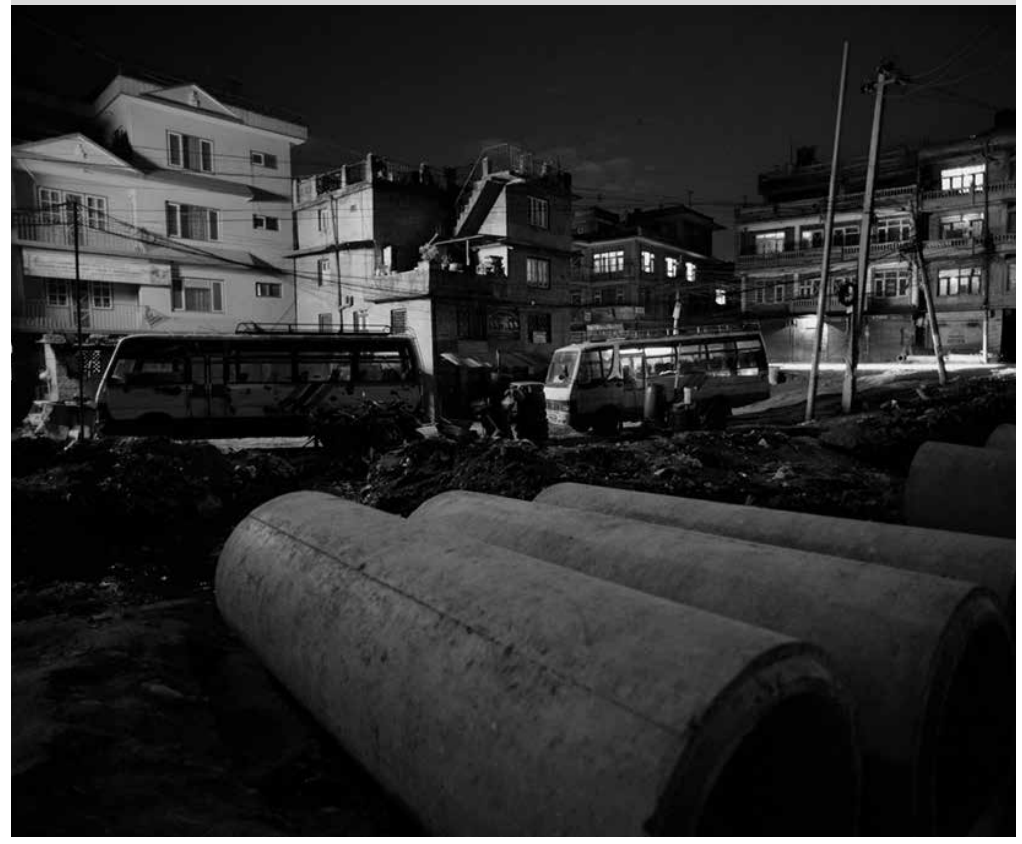


Notes on Contributors

Introduction: Beyond Aid - The Future of Development Cooperation Jing Gu and Naohiro Kitano

Potential and Challenges for Emerging Development Partners: The Case of Indonesia

Akio Hosono

Chains of Knowledge Creation in the Evolution of New Donors

Yasutami Shimomura and Wang Ping

Estimating China's Foreign Aid Using New Data

Naohiro Kitano

Emerging Economies, Disaster Risk Reduction, and South-South Cooperation: The Case of Mexico

Neil Renwick

India's Role as a Facilitator of Constitutional Democracy

Hiroaki Shiga

Triangular Cooperation in East Asia: Challenges and Opportunities for Japanese Official Development Assistance

Jin Sato

The BRICS Effect: Impacts of South-South Cooperation in the Social Field of International Development Cooperation

Geovana Zoccal Gomes and Paulo Esteves

Perspectives on the Global Partnership for Effective Development Cooperation Xiaoyun Li, Jing Gu, Samuel Leistner and Lídia Cabral

Glossary 


\title{
Introduction: Beyond Aid - The Future of Development Cooperation
}

\author{
Jing $\mathrm{Gu}^{1}$ and Naohiro Kitano ${ }^{2}$
}

Abstract This introduction explains the rationale behind this issue of the IDS Bulletin, and identifies the key issues and research questions addressed by the contributors. In so doing, it identifies the emerging outlook of future international development cooperation, such as the new model, approaches, and characteristics of international development cooperation embodied by the traditional and emerging donors. This introduction notes the economic, political, and development trajectories of international development cooperation, and explores how the changing dynamics affect the future of these partnerships. It also presents the central argument that runs throughout the studies; namely, that whilst the 'emerging economies' have excited worldwide attention, and scholarly and policy interest, there has been an over-concentration on a limited number of 'emerging donors', particularly the BRICS economies, a consequential neglect and underestimation of the importance of the wider range of 'new donors', and a pressing need for a more holistic approach to analysis and understanding.

Keywords: development cooperation, global partnership, knowledge creation, emerging donors, BRICS, China, India, Indonesia, Japan, Mexico.

This issue examines the breadth and diversity of what have come to be termed 'emerging donors', and seeks to provide a counter to a debilitating asymmetry in the existing conventional analysis, understanding, and policy approach to these donors. The respective studies in this IDS Bulletin explore this in the context of an evolving international understanding of development assistance that seeks to move 'beyond aid' to encompass wider economic development as a key component of equitable, inclusive, and innovative sustainable growth. The premise for moving 'beyond aid' is that 'conventional development aid is inadequate to address the bottlenecks to growth in many developing and emerging market economies' (Lin and Wang 2017: 1) with the prescription that 
we need to go well beyond aid and purposefully combine aid, trade, and investment, using all financial instruments available and introducing new and innovative ones to meet the challenges of eliminating poverty and transforming industrial structures toward green and emission-reducing development (ibid:: 1).

Heiner et al. usefully explain that

as an umbrella term, beyond aid describes different aspects of the transformation of development cooperation. The transformation is particularly pronounced in four dimensions where aid is decreasing in relative importance: the proliferation of actors, the diversification of finance, the shaping of rules and policies, and the sharing of knowledge for development (Heiner, Klingebiel and Paulo 2014: 2).

This issue of the IDS Bulletin is a result of a unique collaboration between the Japan International Cooperation Agency (JICA) Research Institute and the Institute of Development Studies (IDS). This collaboration is itself grounded in a shared belief in the value of examining the rapidly changing international development assistance system by applying a wider and holistic lens encompassing the increasingly broad number of 'new' donors. The central argument and thread running through this issue is that whilst the 'emerging economies' have generated worldwide attention, scholarly and policy interest, there has been an over-concentration on a limited number of the 'emerging donors', a consequential neglect and underestimation of the importance of the wider range of 'new donors', and a pressing need for a more holistic analysis and understanding. This collection of studies dedicated to highlighting the actual and potential contribution of a wider range of donors is intended to help compensate for this imbalance in the existing literature, contribute to scholarly understanding, and offer informative insights for practical policy deliberation.

The key themes of this issue include:

the need to acknowledge, explain, and understand more deeply the nature and significance of a broader spectrum of donors; i.e. a truly holistic perspective and approach, evidenced in this issue in the geographical range of countries covered such as India and Indonesia;

the utility of applying innovative analytical methods, models, and frameworks to help explain the complexities of these cooperation relationships;

the importance of domestic experience, and efficient and effective policy administration as conditioning, and in some instances determining, factors in the formulation and implementation of the development cooperation approaches of donors;

the growing significance of cooperation between 'new donors' themselves, beyond high-profile groups such as the BRICS (Brazil, Russia, India, China, and South Africa); and 
the need for a continuing process of data reassessment and updates to underpin continuing research.

Almost two decades have passed since the 'new' providers of development cooperation called 'emerging donors' (who later came to be called 'new development partners' or 'providers of South-South cooperation') began to attract the attention of 'traditional donors'. Initially, 'emerging donors' were regarded as 'rogue aid providers' (Dreher and Fuchs 2011; Naim 2009). Since that initial phase, however, there has been a steady accumulation of scholarly works that have enriched our understanding of the 'emerging donors' (Woods 2008; Rhee 2011; Watson 2014). Consequently, the focus has expanded to cover development assistance activities by BRICS countries as a whole, and comprehensive comparisons of the various features of 'emerging' and 'traditional' donors have been elaborated on as their economic and political roles have solidified (Gu 2017).

More recently still, analysis has refocused to counterbalance the conventional wisdom of treating the BRICS as a homogeneous group. This approach has moved to deconstruct this rather homogenised approach to understanding this group of economies in order to explore and explain the various heterogeneous dimensions - elements of variability that are also a component characteristic of the group's evolution - and the implications of this for the BRICS' own development, as well as for their impact on the wider international system and development assistance community (Gu, Shankland and Chenoy 2016). Moving beyond the BRICS, the latest acronymic group branded by the former Goldman Sach's economist Jim O'Neill, the person to whom authorship of the BRICS acronym is attributed, are the so-called MINT economies of Mexico, Indonesia, Nigeria, and Turkey (BBC 2014).

Despite the extensive and growing literature, analysis, and debate, the current status of knowledge still seems to leave many blind spots, stopping short of asking many relevant questions necessary to delve deeper into the realities of 'emerging donors', and to facilitate cooperative and mutually beneficial relationships between the two camps. For instance, 'emerging donors' have received perfunctory attention, leaving their diverse uniqueness virtually unexplored. Especially, there is a paucity of scholarship focused on the realities of the development cooperation undertaken by many emerging powers other than the BRICIS countries. Even more challenging, there is insufficient empirically-based evidence about the realities of BRICS development cooperation. For example, we are yet to understand the impact of this cooperation, although the rising prominence of emerging donors is keenly felt on the side of 'traditional donors' by its volume of development assistance, and thus it has been one of the main focal points of the debate. The difficulty in assessing the volume of development assistance from emerging donors may arise from the fact that their notion of 'development cooperation' is different from that of Western donors (Bräutigam 2011; Gu 2015); for example, with respect to the role of the state (Gu et al. 2016a, b). This definitional 
cleavage is of increasing importance when more emphasis is placed on the role of development cooperation as a 'catalyst' to invoke private sector resources for development.

Added to this, our knowledge regarding the contribution of 'emerging donors' to the improvement of good governance in developing countries seems sobering. For example, the endeavour by India or emerging democracies such as South Africa, Indonesia, and East European countries for the consolidation of democratic governance in other developing countries has received relatively less attention. One can speculate that behind this paucity of scholarship lies the unwritten assumption that the lessons for development emanate and flow only from Western advanced countries, assuming away the possibility that developing countries can be reliable sources of knowledge and experience relevant for the economic, political, and social development of fellow developing countries. In other words, the normative concerns that have always informed the study of 'emerging donors' were the product of the overestimation by 'traditional donors' of the superiority of their development assistance.

All in all, the task of delving deeper into the 'emerging donors' is made difficult by the very dichotomy of 'emerging and traditional donors'. First, it obscures the enormous diversity in each camp. We can reasonably raise the question of whether the BRICS countries are the representative examples of 'emerging donors'. Second, it emphasises the static picture of the characteristics and the differences of each camp, and obscures the dynamic nature of donors and development cooperation. Lastly, the dichotomy of 'we' and 'they' deflect us from introducing the often neglected but nonetheless important viewpoint: the viewpoint of the recipient of development cooperation.

Bearing that in mind, this collection of studies seeks to remedy these deficiencies of the current status of knowledge about 'emerging donors', by asking the following questions: how diverse are 'emerging donors'? What are the realities of development cooperation by medium-sized emerging powers other than the BRICS? What is the actual picture of the cooperation of 'emerging donors' for the improvement of good governance? How are 'emerging donors' changing over time, and how do they utilise their experience of being the development assistance recipients to elaborate a distinctive understanding of, and practical policy approach to, international development assistance? How do the 'traditional donors' and recipients behave and react to the 'emerging donors'?

Recently, the scholarly and practical debate on 'emerging donors' has gained renewed currency, stimulated by the establishment of the Asian Infrastructure Investment Bank (AIIB) and the BRICS' New Development Bank (NDB), which was initially seen as a head-on challenge to the existing international order of development cooperation. The rationale behind this IDS Bulletin is that the examination of the 
above-mentioned questions will contribute to a holistic assessment of the impact of the rise of the new development partners, and will avoid the conventional terminology and thinking characterised by continuing usage of the framing of 'we and they' or 'self and others'.

Over the last decade, the global development landscape has changed rapidly. There has been a complex mix of economic globalisation and anti-globalisation, new principles, processes and practices, fresh multilateral institutions and agencies, international dialogue, and cooperative agreements, with their centre of gravity in the global South, as well as the global compacts on sustainable development and climate change. This has led governments, practitioners, and academics alike to ask whether it is indeed time to move development policy and practice 'beyond aid'. As noted above, this term is best understood in terms of the evolution and application of a broader notion of development assistance to embrace wider economic development and sustainable growth, including multilateralised financing, premised on principles of equity, inclusivity, and partnership (Reisen 2015).

At the centre of this evolution, China and other emerging powers have emerged as critical players (Mawdsley 2012). They have rapidly expanded the financing programmes of their development cooperation and launched new multilateral initiatives and South-South cooperation (Stuenkel 2013). From discourse to cooperation modalities to new institutions, the emerging powers have served as an influential driver of shifting development paradigms (Qobo and Soko 2015). Furthermore, as a result of its overseas activity, development finance has diversified beyond official development assistance (ODA), entering recipient countries through other channels such as investment and trade.

What are the prospects for a post-2015 global partnership? (Hackenesch and Janus 2014). With the growing role of China, including its 'Silk Roads' initiative (Gu et al. 2014; Gu 2015), and other non-traditional donors such as India (Mawdsley and McCann 2011), many have asked what the future of development cooperation might look like and whether a new SDG global partnership might be possible. With this increasing diversity of actors and flows, the development community now faces difficult questions about how to move forward and 'beyond aid' together, in meaningful and effective partnership.

As a consequence, this issue of the IDS Bulletin examines the diverse providers of development cooperation from various viewpoints. The contributors provide a rich and varied menu of studies around the issue's central themes, bringing fresh insights and understanding into today's rapidly changing domain of development cooperation. The subjects covered in the various articles range from exploring the importance of knowledge in the development cooperation experience of emerging economies such as Indonesia; the challenges involved in the policy formulation and implementation of triangular cooperation within a sometimes contradictory set of processes embedded in 
South-South cooperation (Quadir 2013); the dynamics of 'two-way interaction' between donors and recipients in chains of knowledge creation; and an important reassessment and updating of the critical data upon which estimates of China's foreign aid disbursements are made and understood in international comparison.

A key aspect of these studies is the authors' development and application of fresh analytical approaches with which to deconstruct the complexities of their subjects. For example, Akio Hosono's article deploys an 'Indonesian model' through which to assess the effectiveness and wider applicability to development cooperation; Naohiro Kitano's article utilises the tool of 'regularity' in the reassessment of China's gross disbursements of concessional loans; and Yasutami Shimomura and Wang Ping develop a hypothetical model to explain in detail the processes by which 'knowledge creation' by emerging donors, during the time they receive development assistance, becomes a core component of their approach to development cooperation. Each of the studies provide new perspectives into the specific aspects being addressed by the authors. However, in looking across the studies, one is struck by a common theme, namely the importance the contributors attach to understanding development cooperation as a dynamic relationship; as an interactive process between the partners, requiring a carefully analytical deconstruction of the complex processes at the heart of these evolving relationships. This is perhaps more evident if we introduce each of the articles in a little more detail.

The article by Akio Hosono, entitled 'Potential and Challenges for Emerging Development Partners: The Case of Indonesia', assesses the possible gains as well as the challenges of development cooperation for new development partners, and examines the experience and approach of Indonesia as its case study. The major distinctive features of Indonesia's aid pattern could be summarised as flexible and pragmatic, with significant emphasis on technical cooperation, and without a strong regional or specific-country focus. The particular interest of the study is in the component of the knowledge of emerging partners in development cooperation. Hosono's main argument is that there is an enormous potential impact to be realised from the accumulated knowledge of the global South, but only if it is mobilised to its fullest extent. To achieve this goal, the author argues that a critical issue is 'to identify and make available knowledge that is valuable to those countries that need it'. In addition to this potential, the article also notes the significant challenges involved.

The importance of the knowledge component of emerging partners in development cooperation is also the central focus of the article by Yasutami Shimomura and Wang Ping, 'Chains of Knowledge Creation in the Evolution of New Donors'. In this closely argued account, the authors examine and assess the relationship between aid receiving and giving. The study illustrates the importance of recognising and explaining the way that aid recipients have created knowledge during 
the time they receive aid, and the potential contributions of emerging donors based on their 'knowledge creation' during this receiving of aid. Drawing on a number of interesting and valuable case studies, the authors' analysis finds that there is 'two-way interaction' that operates in the donor-recipient relationship which contributes to the process of knowledge creation. Based on this important insight, the study concludes that sharing this experience and knowledge of receiving aid with other developing economies can offer an important source of strength as traditional donors essentially lack this source of influence.

The study provides an important contribution to our understanding of the way that emerging economies as recipients of aid 'nurture' the knowledge they gain through these chains of knowledge creation, and then seek to apply it to other countries through their own financial and technical cooperation. Also investigating development cooperation primarily with a focus on it being a relationship, Jin Sato's article, 'Triangular Cooperation in East Asia: Challenges and Opportunities for Japanese Official Development Assistance', presents a critique of the way that triangular cooperation works in practice, assessing the balance sheet of potential benefits and challenges it presents. The study addresses an important issue by seeking to explain the ability of East Asian economies to transform ODA institutions. Whilst there is diversity across the policy and practice of Japan, China, and South Korea and these have been subject to substantial discussion and critique, it is perhaps surprising that their combined cooperative relationships have been much less examined. The study focuses on the experiences of JICA, centring on the political dimension and policy formulation, and explains what Sato argues is the 'central importance' of power for our closer understanding of how development assistance relationships begin, sustain, and evolve.

Drawing upon case study evidence, the author argues that triangular cooperation represents a new means by which some donors aim to keep their relationships with emerging powers. Where this operates, the analysis indicates that South-South cooperation, including triangular cooperation, is inherently contradictory due to the realities of power embedded in it, and that primarily this is 'an effort by the North to support South-South cooperation'. The study argues that co-financing rather than triangular cooperation offers a potentially more fruitful avenue to respond to this challenge. Sato's study argues that co-financing cooperation can have a positive impact on development cooperation efficiency and effectiveness. However, the study indicates that JICA's experience demonstrates how constraints can operate, for example, in the requirement for prior administrative clearance and a rapid turnover of staff that work to disrupt policy continuity.

Naohiro Kitano's article, 'Estimating China's Foreign Aid Using New Data', provides an important update and corrective to earlier assessments. The stated aim of the study is to provide 'updated estimates of China's foreign aid volumes between 2001 and 2014'. 
This serves as a proxy for China's ODA defined by the Development Assistance Committee (DAG) of the Organisation for Economic Co-operation and Development (OECD), and can be used to compare the results with the ODA of other DAC members. It applies a modified methodology to estimate the gross disbursements of concessional loans in the period under review. The principal finding is that there may be a 'weak regularity' within a cumulative amount of the framework loan agreement, the project loan agreement, and the gross disbursement of concessional loans.

Working from this fresh data, the study provides fresh insight and understanding into China's foreign aid volumes in 2012 and 2013. Kitano's study convincingly demonstrates that China's foreign aid volumes were rather less than had previously been assessed. This carries implications for the comparative ranking of disbursements of concessional loans. The analysis indicates that, whilst China was ranked number six for these years, the more accurate ranking is at tenth in 2012 and ninth in 2013. This study provides an analytical update and represents an important adjustment carrying substantial weight in deepening our knowledge and understanding for the comparative assessment of ODA disbursements, multilateral aid, and administrative budgeting for grants and loans.

Reflecting the aim of this issue of the IDS Bulletin to broaden the focus of development cooperation and the 'new donors', the article by Neil Renwick entitled 'Emerging Economies, Disaster Risk Reduction, and South-South Cooperation: The Case of Mexico' examines the contribution of Mexico to reducing the risk of natural disasters. Mexico is a so-called 'MINT' emerging economy with a high-risk exposure to disaster. The study explains Mexico's substantial commitment to domestic disaster risk reduction and effective engagement in regional and global disaster risk management and development cooperation. The finding of the article is that Mexico's story not only has many important positive aspects to contribute to South-South cooperation knowledge-sharing and international development cooperation, but it also demonstrates the continuing challenges of financing, administration, and politics for emerging and developing economies.

The role of the emerging economies in development cooperation attracts widespread interest, and the questions of how these economies can contribute and how far this is distinctive have generated substantial debate. The key interest of Hiroaki Shiga's article, 'India's Role as a Facilitator of Constitutional Democracy', is in analysing governance in developing countries. The core research question that Shiga poses is 'How can the unique experiences, institutions, norms, and ideas of developing countries contribute to the development and good governance of other developing countries?'. In an illuminating study that challenges conventional wisdom and offers a new perspective, the article provides a forensic analysis of the principal characteristics of Indian democratic governance and, particularly, constitutional government. 
Building upon the important insights into India's political infrastructure and political culture, the study then moves on to explore and assess India's role in democratic facilitation and promotion in the context of development assistance. The central argument being put forward through the study is that India's constitutional system and qualities of governance place it in a 'unique' position to contribute to good governance in other developing countries. This role and its significance, it is argued, has been largely 'underestimated' in the conventional literature and wisdom. Challenging this established viewpoint, the article details the extensive countervailing evidence of India's development cooperation; for example, in its provision of constitutional articulation and drafting.

Following on from this study of India, two articles broaden the analytical scope. The first of these, by Geovana Zoccal Gomes and Paulo Esteves, addresses the impact of the BRICS group of economies as a component of South-South cooperation. Entitled 'The BRICS Effect: Impacts of South-South Cooperation in the Social Field of International Development Cooperation', the article considers the effect of South-South cooperation in the established principles and practices of development cooperation, globally and locally. Using an innovative application of a mode of analysis, combining the Bourdieusian concept of social fields with current international relations perspectives, the article works from the premise that international development cooperation is better understood and explained as a social field. In this respect, the authors argue that emerging economies such as the BRICS offer South-South cooperation as an alternative model for development.

The second article broadening the scope of analysis is 'Perspectives on the Global Partnership for Effective Development Cooperation' by Xiaoyun Li, Jing Gu, Samuel Leistner, and Lídia Cabral. The article seeks to identify the reasons behind global development cooperation and the challenges which arise. The authors argue that the Global Partnership for Effective Development Co-operation (GPEDG) created a unique opportunity to combine the advantages and different approaches of North-South and South-South cooperation. The study presents a distinctive critique of GPEDC, putting forward a strong case that the GPEDC has been weakened by a lack of support from both the North and South, resulting from a lack of trust and because of misconceptions among the partner countries. The article specifically explains the withholding of support for the GPEDC by the rising powers, by applying a perspective highlighting the difference between South-South cooperation and the approach of Southern development assistance within it, and North-South cooperation with ODA by the OECD-DAC. The authors argue that the bedrock of a convincing analysis of effective development cooperation and the contribution of the emerging economies is, necessarily, the availability of reliable, testable data contributing to a deeper and more convincing foundation for both scholarly and policy understanding. 
Based on the fresh insights and new understanding offered by these studies, this issue of the IDS Bulletin helps to advance the scholarly study of the new providers of development cooperation, firstly, by critically reviewing the conventional wisdom and, secondly, by introducing new perspectives. More fundamentally, this issue questions the explicit and implicit underlying assumptions in examining the issue of development cooperation: namely, the dichotomy of 'traditional' and 'emerging' donors, and the dominance of superior knowledge, technologies, institutions, and experience of Western countries. The underlying hope is that this IDS Bulletin will also contribute to the enhancement of a better mutual understanding of 'traditional' and 'emerging' donors, and thus to the constructive engagement of both camps; for example, in terms of a continuing process of dialogue on knowledge-sharing, financing, and inclusive growth.

\section{Notes}

1 Director of the Centre for Rising Powers and Global Development (CRPD) and Research Fellow, Institute of Development Studies.

2 Professor, Global Center for Science and Engineering, WASEDA University.

\section{References}

BBC (2014) 'The Mint Countries: Next Economic Giants?' BBC Magazine, 6 January, www.bbc.co.uk/news/magazine-25548060 (accessed 8 May 2018)

Bräutigam, D. (2011) 'Aid "With Chinese Characteristics": Chinese Foreign Aid and Development Finance Meet the OECD-DAC Aid Regime', Fournal of International Development 23.5: 752-64

Dreher, A. and Fuchs, A. (2011) Rogue Aid? The Determinants of China's Aid Allocation, Princeton NJ: Department of Politics, Princeton University, www.princeton.edu/politics/about/file-repository/public/RogueAid-China-Aid-Allocation.pdf (accessed 7 May 2018)

Gu, J. (2017) 'China and the Emerging Economies', in P. Haslam, J. Schafer and P. Beaudet (eds), Introduction to International Development: Approaches, Actors and Issues, 3rd ed., Toronto: Oxford University Press Canada

Gu, J. (2015) China's New Silk Road to Development Cooperation: Opportunities and Challenges, Tokyo: United Nations University-Centre for Policy Research (UNU-CPR)

Gu, J.; Chuanhong, Z.; Vaz, A. and Mukwereza, L. (2016a) 'Chinese State Capitalism? Re-Thinking the Role of the State and Business in Chinese Development Cooperation in Africa', Open Access Special Issue, World Development 81: 24-34

Gu, J.; Shankland, A. and Chenoy, A. (eds) (2016b) The BRICS in International Development, London: Palgrave Macmillan

Gu, J.; Li, X.; Zhang, X. and Bloom, G. (2014) 'China and International Development: Challenges and Opportunities', IDS Bulletin 45.4, http://bulletin.ids.ac.uk/idsbo/issue/view/22 (accessed 11 June 2018)

Hackenesch, C. and Janus, H. (2014) 'Emerging Economies in the Post-2015 Negotiations: How their Positioning will Shape the New 
Agenda', in T. Fues and J. Ye (eds), The United Nations Post-2015 Agenda for Global Development: Perspectives from China and Europe, 1st ed., Bonn: German Development Institute, www.die-gdi.de/uploads/media/ Studies_84.pdf (accessed 18 January 2017)

Heiner, J.; Klingebiel, S. and Paulo, S. (2014) 'Beyond Aid' and the Future of Development Cooperation, Briefing Paper 6/2014, Bonn: German Development Institute, www.die-gdi.de/en/briefing-paper/article/ beyond-aid-and-the-future-of-development-cooperation/ (accessed 7 May 2018)

Lin, J. and Wang, Y. (2017) 'Introduction and Objectives', in J. Lin and Y. Wang (eds), Going Beyond Aid: Development Cooperation for Structural Transformation, Cambridge: Cambridge University Press

Mawdsley, E. (2012) From Recipients to Donors: Emerging Powers and the Changing Development Landscape, London: Zed Books

Mawdsley, E. and McCann, G. (eds) (2011) India in Africa: Changing Geographies of Power, Cape Town: Pambazuka Press

Naim, M. (2009) 'Rogue Aid', Foreign Policy, 15 October, http://foreignpolicy.com/2009/10/15/rogue-aid/ (accessed 7 May 2018)

Qobo, M. and Soko, M. (2015) 'The Rise of Emerging Powers in the Global Development Finance Architecture: The Case of the BRICS and the New Development Bank', South African fournal of International Affairs 22.3: 277-88

Quadir, F. (2013) 'Rising Donors and the New Narrative of "South-South" Cooperation: What Prospects for Changing the Landscape of Development Assistance Programmes?', Third World Quarterly 34.2: 321-38

Reisen, H. (2015) 'Will the AIIB and the NDB Help Reform Multilateral Development Banking?', Global Policy 6.3: 297-304

Rhee, H. (2011) 'Promoting South-South Cooperation through Knowledge Exchange', in H. Kharas, K. Makino and W. Jung (eds), Catalyzing Development: A New Vision for Aid, Washington DC: Brookings Institution

Stuenkel, O. (2013) Institutionalizing South-South Cooperation: Towards a New Paradigm? Background Research Paper, submitted to the High Level Panel on the Post-2015 Development Agenda, www.post2015hlp.org/wp-content/uploads/2013/05/Stuenkel_ Institutionalizing-South-South-Cooperation-Towards-a-NewParadigm.pdf (accessed 11 February 2017)

Watson, I. (2014) Foreign Aid and Emerging Powers: Asian Perspectives on Official Development Assistance, Abingdon, Oxon: Routledge

Woods, N. (2008) 'Whose Aid? Whose Influence? China, Emerging Donors and the Silent Revolution in Development Assistance', International Affairs 84.6: 1205-21 
